\title{
Circulating low-density lipoprotein ceramide concentrations increase in Holstein dairy cows transitioning from gestation to lactation
}

\author{
A. N. Davis, ${ }^{1,2}$ J. E. Rico, ${ }^{1,2}$ W. A. Myers,,${ }^{1,2}$ M. J. Coleman, ${ }^{2}$ M. E. Clapham, ${ }^{2}$ N. J. Haughey, ${ }^{3}$ \\ and J. W. McFadden ${ }^{1,2 *}$ \\ ${ }^{1}$ Department of Animal Science, Cornell University, Ithaca, NY 14853 \\ ${ }^{2}$ Division of Animal and Nutritional Sciences, West Virginia University, Morgantown 26505 \\ ${ }^{3}$ Department of Neurology, Johns Hopkins University School of Medicine, Baltimore, MD 21287
}

\section{ABSTRACT}

Low-density lipoprotein (LDL) ceramide causes insulin resistance in obese diabetic nonruminants. Because previous work suggests that liver-derived ceramide may impair insulin action in postpartum cows, our objectives were to characterize peripartal changes in lipoprotein ceramides. We further studied the effects of prepartum adiposity on lipoprotein ceramide levels. Twenty-eight pregnant Holstein cows (parity $=3.65 \pm$ 1.62) with lean (body condition score, $\mathrm{BCS}=2.97 \pm$ 0.16 ; body weight, $\mathrm{BW}=630 \pm 55.2 \mathrm{~kg} ; \mathrm{n}=15$ ) or overweight $(\mathrm{BCS}=3.93 \pm 0.27 ; \mathrm{BW}=766 \pm 46.1 \mathrm{~kg}$; $\mathrm{n}=13$ ) body condition $28 \mathrm{~d}$ before expected parturition were evaluated. Sampling occurred on d -20.5 $\pm 1.74,-13.8 \pm 1.71,-7.84 \pm 4.07,-6.71 \pm 1.00$, $-3.92 \pm 0.64$, and $-1.28 \pm 0.61$ (before parturition); daily until d 8 postpartum; and on d 10, 12, 14, 21, and 28. Adipose tissue and liver were biopsied on $\mathrm{d}$ $-7.84 \pm 4.07$ and 10. Postpartum insulin sensitivity was assessed using the hyperinsulinemic-euglycemic clamp. Lipoprotein fractions were isolated using liquid chromatography. Sphingolipids were quantified using mass spectrometry. Data were analyzed using a mixed model with repeated measures. Overweight cows had a higher BCS and BW at enrollment relative to lean cows, but BCS and BW were similar postpartum. Overweight cows lost more body condition $(0.97 \pm 0.36$ vs. $0.55 \pm 0.16 \mathrm{BCS}$ units) and $\mathrm{BW}(291 \pm 67.3$ vs. $202 \pm 54.5 \mathrm{~kg}$ ) during transition relative to lean cows. Adipocyte volume and counts declined from prepartum to postpartum (50.4 and $13.7 \%$, respectively), and adipocyte volume was greater $(48.2 \%)$ in overweight cows

Received October 15, 2018.

Accepted February 4, 2019.

*Corresponding author: jwm43@cornell.edu prepartum relative to lean cows. Although DMI was comparable between BCS groups, milk yield tended to be greater in overweight cows. Plasma free fatty acid and $\beta$-hydroxybutyrate and liver lipid levels were 40, 16 , and $37 \%$ greater, respectively, in overweight cows compared with lean cows. Glucose infusion rate during the hyperinsulinemic-euglycemic clamp tended to be lower in overweight cows. Ceramide levels within triacylglycerol-rich lipoprotein fractions declined postpartum, whereas LDL ceramide increased postpartum. Overweight cows had lower triacylglycerol-rich lipoprotein C16:0-ceramide levels relative to lean cows. Prepartum LDL C24:0-ceramide levels were greater in overweight cows relative to lean cows. Independent of prepartum adiposity, we concluded that serum LDL ceramide levels are elevated in early-lactation cows experiencing adipose tissue free fatty acid mobilization and hepatic steatosis.

Key words: ceramide, lipoprotein, periparturient cow

\section{INTRODUCTION}

The ability of the liver to de novo synthesize ceramide in response to an oversupply of free fatty acids (FFA) has been established in humans and rats (Holland et al., 2007; Watt et al., 2012). In turn, ceramide is secreted within very low density lipoproteins (VLDL; Merrill et al., 1995; Watt et al., 2012). Of particular interest, low-density lipoprotein (LDL) ceramide has been identified as a mediator of insulin resistance in nonruminants (Boon et al., 2013). Specifically, LDL containing either C16:0- or C24:0-ceramide decreases systemic and skeletal muscle glucose uptake by inhibiting insulin-stimulated protein kinase B phosphorylation (Boon et al., 2013). Of clinical relevance, the severity of insulin resistance develops with plasma ceramide accumulation in obese humans with type 2 diabetes (Haus et al., 2009).

Dairy cows transitioning from gestation to lactation experience a progressive decline in insulin action to sup- 
port milk synthesis (Bauman and Currie, 1980). One explanation is the uncoupling of the somatotropin-IGF axis, which maintains heightened levels of circulating somatotropin with suppressed levels of the insulin sensitizer IGF-1 (Thissen et al., 1994). In parallel or alternatively, ceramide may be involved in modulating insulin action. This possibility is merited because circulating ceramide concentrations increase during the transition from gestation to lactation. This response is particularly evident in postpartum cows that mobilize more body fat, such as those with elevated prepartum adiposity (Rico et al., 2015, 2017). Moreover, plasma ceramide levels are positively correlated with FFA supply (Rico et al., 2015, 2018a; Davis et al., 2017), which is relevant considering that somatotropin enhances lipolysis (Sechen et al., 1990). Specifically, whole-plasma very long chain ceramides (e.g., C24:0-ceramide) often display the greatest postpartum increases that parallel circulating FFA supply; however, C16:0-ceramide concentrations concomitantly decrease. Circulating very long chain ceramides are also inversely related to direct measures of insulin sensitivity (Davis et al., 2017; Rico et al., 2017), a response not observed for plasma C16:0-ceramide. However, within the context of previous work (Boon et al., 2013; Hla and Kolesnick, 2014), our prior observations suggest that LDL C16:0 -ceramide may antagonize insulin signaling in bovine skeletal muscle tissue postpartum. Such a response is plausible when we consider the ability of ceramide to downregulate insulin-stimulated 2-deoxyglucose uptake and insulin-stimulated protein kinase B phosphorylation in primary bovine adipocytes cultured in nutrient excess (Rico et al., 2018b).

Considering the associative and causative roles of C16:0- and C24:0-ceramide during the development of insulin resistance in obese nonruminants (Haus et al., 2009; Boon et al., 2013) and dairy cows (Rico et al., 2015, 2017; Davis et al., 2017), our objectives were to characterize changes in LDL C16:0- and C24:0-ceramide concentrations during the peripartum period and to determine whether these changes are related to prepartum adiposity status as classified by BCS (Wildman et al., 1982). To achieve our objectives, we used a previously developed size exclusion chromatography by fast protein liquid chromatography (SEC-FPLC) method to isolate lipoproteins for ceramide quantification by liquid chromatography and tandem MS (Wiesner et al., 2009; Phipps et al., 2017). Our hypotheses were that circulating LDL ceramide concentrations would increase during the periparturient period and that heightened prepartum adiposity would predispose cows to greater LDL ceramide levels with parallel increases in circulating FFA and liver lipid deposition.

\section{MATERIALS AND METHODS}

\section{Experimental Design}

Experimental procedures were approved by the West Virginia University Institutional Animal Care and Use Committee (Morgantown). The experiment was completed at Dovan Farms (Berlin, PA), a West Virginia University agricultural research and education partner and 700-Holstein cow commercial dairy farm. Twenty-eight pregnant multiparous (parity $=3.65 \pm$ 1.62) Holstein dairy cows with a lean (BCS $=2.97 \pm$ $0.16 ; \mathrm{BW}=630 \pm 55.2 \mathrm{~kg} ; \mathrm{n}=15$ ) or overweight (i.e., overconditioned, $\mathrm{BCS}=3.93 \pm 0.27 ; \mathrm{BW}=766 \pm 46.1$ $\mathrm{kg} ; \mathrm{n}=13$ ) body condition $28 \mathrm{~d}$ before expected parturition (i.e., enrollment) were evaluated through d 28 postpartum. Cows were randomly selected within the criteria that lean and overweight cows exhibited a BCS $\leq 3.25$ and $\geq 3.75$ at $28 \mathrm{~d}$ before expected parturition, respectively. Cows were individually housed in strawbedded pens through d 12 and then moved to adjacent freestalls thereafter due to management constraints of the commercial operation. Cows were ad libitum fed a corn silage-based TMR twice daily (0700 and $1700 \mathrm{~h}$ ) to meet or exceed nutrient recommendations for gestation and lactation (CNCPS, version 6.1; Cornell University, Ithaca, NY). Daily orts were maintained between 5 and 10\%. Cows were milked twice daily (0600 and $2030 \mathrm{~h}$ ) using a portable milking unit from parturition through d 12 and then thrice daily $(0430,1230$, and $2030 \mathrm{~h}$ ) for the remainder of the study evaluation (d 13-28). Cow BW and BCS were recorded weekly. Body condition score was performed using a 5-point scale (Wildman et al., 1982) and presented as the average between a minimum of 2 trained investigators.

Preprandial blood samples $(10 \mathrm{~mL})$ were collected via coccygeal venipuncture weekly starting at enrollment until $\mathrm{d}-7$ before expected calving, then daily until d 8 postpartum, followed by d 10, 12, 14, 21, and 28 postpartum. Blood samples were either placed on ice or stored at $37^{\circ} \mathrm{C}$ for 30 min until centrifugation at $3,400 \times g$ for 10 min at $4^{\circ} \mathrm{C}$ for the collection of plasma or serum, respectively. Samples were initially stored at $-20^{\circ} \mathrm{C}$ and then transferred on dry ice to $-80^{\circ} \mathrm{C}$ for long-term storage. Adipose and liver biopsies were performed on $\mathrm{d}-12$ before expected calving and $\mathrm{d} 10$ postpartum. For adipose tissue biopsies, a 2.5- to 3.8$\mathrm{cm}$ cutaneous incision was made lateral to the base of the tail head around the pin bones using a sterile blade until subcutaneous adipose tissue was visible. Sterile forceps were used to collect approximately 10 to $20 \mathrm{~g}$ of subcutaneous adipose tissue. For histological analyses, a subcutaneous adipose explant was harvested, placed 
in a cassette, and stored in formalin. For liver biopsies, a $0.5-\mathrm{cm}$ incision was made through the skin within the 11th intercostal space. Using a custom trocar, approximately $1 \mathrm{~g}$ of liver tissue was collected (Hughes, 1962) and snap-frozen in liquid nitrogen. Within $48 \mathrm{~h}$, biopsy samples were removed from liquid nitrogen and stored at $-80^{\circ} \mathrm{C}$. After tissue collection, biopsy sites were cleaned with hydrogen peroxide, stapled, and sprayed with antiseptic (Blu-Kote; H. W. Naylor Co. Inc., Morris, NY). Milk samples were collected at each milking on $\mathrm{d} 1,3,5,7,10,12,14,21$, and 28 relative to parturition. Milk samples were stored at $4^{\circ} \mathrm{C}$ and preserved using bronopol tablets (D\&F Control Systems, San Ramon, CA) for milk composition analysis within 1 wk. Samples of TMR were composited monthly for analysis.

The hyperinsulinemic-euglycemic clamp (HEC) was performed on d 12 postpartum. Two jugular catheters (Micro-Renathane Implantation Tubing, $2.03 \mathrm{~mm}$ o.d. $\times 1.02 \mathrm{~mm}$ i.d.; Braintree Scientific Inc., Braintree, MA; Schoenberg et al., 2012) were inserted the evening before the HEC and flushed with heparinized saline every $7 \mathrm{~h}$ to maintain patency. One catheter was used for blood sampling, and the other, in the opposite jugular vein, was used for insulin and glucose infusion. Infusion lines were attached to the same catheter using an antiy port (Millpledge North America Inc., Agoura Hills, CA). The insulin solution was prepared using bovine insulin stock solution $(1 \mathrm{mg} / \mathrm{mL}$; Humulin R; Lilly and Co., Indianapolis, IN), sterile saline, and harvested plasma for insulin infusates (2.5\% of total solution volume; DeFronzo et al., 1979). To calculate insulin dose, BW was recorded once daily for $2 \mathrm{~d}$ before the HEC and averaged. Feed was removed $2 \mathrm{~h}$ before the start of the HEC, which occurred before the morning feeding. An insulin priming dose was introduced intravenously to increase blood insulin levels (DeFronzo et al., 1979). Subsequently, infusion lines were attached and insulin $(1 \mu \mathrm{g} / \mathrm{kg}$ of BW, $27 \mathrm{IU} / \mathrm{mg}$ at $9.0 \mathrm{~mL} / \mathrm{h})$ was administered using a syringe pump (New Era Pump Systems Inc., Farmingdale, NY). Concurrently, glucose (50\% dextrose solution) was infused using a Macro XL Plum Pump (Abbott Laboratories, North Chicago, IL) at 9 $\mathrm{mL} / \mathrm{h}$ until insulin noticeably decreased blood glucose levels measured by a hand-held glucometer (Precision Xtra, Abbott Diabetes Care Inc., Alameda, CA). Glucose infusion rate was adjusted variably to reach and maintain a steady-state euglycemia for $30 \mathrm{~min}$ minimum. The target steady-state range was considered to be the average of 5 basal glucose concentrations immediately before HEC. The steady state range extended $\pm 10 \%$ beyond this basal average. The resulting steady- state glucose infusion needed to maintain euglycemia was a reflection of insulin action.

\section{Sample Analyses}

Total mixed ration DM contents were determined by drying at $60^{\circ} \mathrm{C}$ until static weights were achieved. Additional TMR samples were submitted to a commercial laboratory for nutrient composition by near-infrared spectroscopy (Cumberland Valley, Cumberland, MD; AOAC International, 1995, method 989.03). Milk samples were analyzed for true protein, lactose, and fat concentrations by mid-infrared procedures and SCC by flow cytometry within 1 wk of collection (Dairy One, Ithaca, NY).

Plasma glucose, FFA, and BHB concentrations were measured using enzymatic kits (no. 997-03001 Autokit Glucose; no. 999-34691, no. 995-34791, no. 991-34891, and no. 993-35191 HR Series NEFA-HR (2); and no. 417-73501 and no. 413-73601 Autokit 3-HB, respectively; Wako Chemicals USA Inc., Richmond, VA). Serum insulin concentrations were determined using ELISA (no. 10-1201-01, Mercodia Bovine Insulin ELISA; Mercodia AB, Uppsala, Sweden). All spectrophotometric measurements were conducted using a SpectraMax Plus 384 Microplate Reader (Molecular Devices, Sunnyvale, CA). Intra- and interassay coefficients of variation were 3.92 and $3.43 \%, 2.85$ and $7.35 \%, 2.42$ and $9.07 \%$, and 4.74 and $17.0 \%$ for glucose, FFA, BHB, and insulin, respectively. Adipose tissue stored in formalin was processed by a trained pathologist using a tissue processor within the Pathology Laboratory for Translational Medicine (West Virginia University, Morgantown). The tissue was embedded using molten paraffin, allowed to harden on a cryo console, and then stored at $4^{\circ} \mathrm{C}$ until slicing. Before staining, slides were deparaffinized using xylene, and the nucleus and cytoplasm were stained with hematoxylin and eosin, respectively. Once the slides were fixed, images were taken at $200 \times$ magnification through a microscope, and adipocyte volume and counts were recorded using Image $J$ software (National Institutes of Health, Bethesda, MD). Liver lipid was extracted and quantified using previously described methods (Hara and Radin, 1978; Piepenbrink and Overton, 2003).

Using methodology described by Phipps et al. (2017), SEC-FPLC was applied to isolate bovine serum fractions containing lipid-containing triacylglycerol (TAG)-rich lipoproteins (i.e., VLDL and chylomicrons), LDL, and buoyant high-density lipoprotein (HDL) subclasses. Sphingolipids within TAG-rich lipoprotein, LDL, and buoyant HDL fractions were quantified by liquid chro- 
matography and tandem MS using methods previously described (Rico et al., 2015, 2017). Dense HDL fractions were not analyzed because they were not the focus of this investigation. The purpose of including analysis of the buoyant HDL fraction is to provide evidence that our method is comparable with previous findings (Phipps et al., 2017). This combination of techniques is routinely used in nonruminants to quantity lipoprotein ceramide (Wiesner et al., 2009; Kontush and Chapman, 2010; Boon et al., 2013). The SEC-FPLC fractions were also analyzed in duplicate for TAG (no. T7532; Pointe Scientific Inc., Canton, MI), total cholesterol, and total phospholipid using commercial enzymatic kits (no. 99902601 Cholesterol E and no. 997-01801 Phospholipid C, respectively; Wako Chemicals USA Inc.). Spectrophotometric measurements were conducted using a SpectraMax Plus 384 Microplate Reader. Intra- and interassay coefficients of variation were 1.44 and $1.3 \%$, 1.16 and $4.15 \%$, and 1.51 and $3.14 \%$ for $\mathrm{TAG}$, total cholesterol, and total phospholipids, respectively.

\section{Calculations and Statistical Analyses}

The insulin sensitivity index (SI) was calculated as follows (Muniyappa et al., 2007):

$$
\begin{aligned}
\mathrm{SI}_{\text {Clamp }} & =\text { glucose infusion rate } /[\text { (steady-state glucose }) \\
& \times(\text { steady-state insulin }- \text { basal insulin })]
\end{aligned}
$$

Plasma and serum data were analyzed using a mixed model with repeated measures in SAS (version 9.3; SAS Institute Inc., Cary, NC). The model included the random effect of cow and the fixed effects of BCS, day relative to parturition, and their interaction. The SLICE effect was used to analyze BCS differences by time. Studentized residuals $<-3$ or $>3$ were considered outliers and were removed from the data set (typically no more than 2 per analysis). When the residuals were not normally distributed, data were transformed using the natural logarithm and presented in the original scale. Parametric Pearson correlations were performed to determine associations between circulating lipoprotein ceramides and FFA. The significance level was set at $P \leq 0.05$, and trends toward significance were considered at $0.05<P \leq 0.10$.

\section{RESULTS AND DISCUSSION}

Cows were fed gestation and lactation diets primarily comprising corn silage, grass haylage, grass hay, and concentrates (Supplemental Table S1; https://doi .org/10.3168/jds.2018-15850). Actual prepartum days of sampling for plasma glucose, FFA, and BHB data presented were $\mathrm{d}-20.5 \pm 1.74,-13.8 \pm 1.71,-6.71$ $\pm 1.00,-3.92 \pm 0.64$, and $-1.28 \pm 0.61$ before parturition. Actual prepartum day of biopsy and serum lipoprotein measurement was $-7.84 \pm 4.07$. Three cows were removed from the study (1 displaced abomasum, 1 severe mastitis, and 1 cessation of eating after liver biopsy). Therefore, our evaluation compared 14 lean $(\mathrm{BCS}=2.96 \pm 0.16 ; \mathrm{BW}=632 \pm 56.9)$ and 11 overweight $(\mathrm{BCS}=3.93 \pm 0.30 ; \mathrm{BW}=781 \pm 33.8)$ cows.

Adipose tissue lipolysis ensues as dairy cattle transition from gestation to lactation, and cows with elevated prepartum adiposity experience greater elevations in circulating FFA (Bell, 1995; Rico et al., 2015). Confirming the adequacy of our experimental design, BCS at enrollment was significantly different between lean $(2.96 \pm 0.16)$ and overweight $(3.93 \pm 0.30)$ cows $(P$ $<0.01$ ). All cows experienced peripartal reductions in BCS and BW $(P<0.01$; Figure $1 \mathrm{~A}$ and $\mathrm{B}$, respectively), more so for cows with greater BCS at enrollment (e.g., 29\% decrease in BCS compared with lean from d -21 to 28 relative to calving; $P<0.01$; Figure $1 \mathrm{~A}-\mathrm{D}$ ). Subcutaneous adipocyte volume and counts decreased from pre- to postpartum for all cows $(P<0.01$; Figure $2 \mathrm{~A}$ and $\mathrm{B}$, respectively), whereas overweight cows had greater subcutaneous adipocyte volume relative to lean cows prepartum $(P<0.05)$. Additionally, overweight cows experienced a $59 \%$ loss in adipocyte volume during the transition period compared with a $37 \%$ loss observed in lean cows. Because we did not detect a difference in DMI between adiposity groups, reductions in BCS and adipocyte volume in cows classified as overweight prepartum were likely not due to differences in DMI (Supplemental Figure S1; https://doi.org/10 .3168/jds.2018-15850). Supporting the possibility that overweight cows experience greater lipolytic rates, De Koster et al. (2016) found that larger fat cells have higher basal and isoproterenol-stimulated lipolytic activity. Because overweight cows provide more FFA substrate for $\beta$-oxidation by peripheral tissues, glucose may be spared for milk production. As supported by others (Roche et al., 2006, 2007; McCarthy et al., 2007), we did observe a tendency for enhanced milk yields in overweight cows $(P<0.10$; Supplemental Figure S2A; https://doi.org/10.3168/jds.2018-15850). We emphasize that this observation occurred in overweight cows not diagnosed with a clinical disease at the time of sampling. We also observed increased milk fat and lactose yields $(P<0.01 ;$ Supplemental Figure S2B and $\mathrm{F}$, respectively) and enhanced milk fat content in cows with elevated prepartum BCS $(P<0.05$; Supplemental Figure S2C). Marked elevations in milk fat yield and content were likely due to increased incorporation of adipose-derived FFA into milk fat. Milk protein yield and percentage and milk lactose content were not in- 
fluenced by prepartum adiposity (Supplemental Figure S2D, E and G, respectively).

Although prepartum BCS did not modify plasma glucose concentrations (Figure 3A), circulating glucose reached its highest concentration for all cows at parturition and was lowest during the immediate postpartum period $(P<0.01)$. Postpartum reductions in circulating glucose developed with robust elevations in plasma FFA levels (Figure 3B; $P<0.01$ ), which was more pronounced in cows with greater body condition during late gestation $(P<0.01)$. Although acute, overweight cows experienced a $74 \%$ increase in plasma FFA concentrations at parturition relative to lean cows. As expected, elevated plasma FFA levels in overweight cows were accompanied by increased liver lipid accumulation and plasma BHB levels during the peripartum period (Figure 4A and B, respectively; $P<0.05$ ). Such outcomes are reflective of metabolic impairment caused by heightened prepartum adiposity and have been previously observed (Fronk et al., 1980; Treacher et al., 1986; Gearhart et al., 1990).
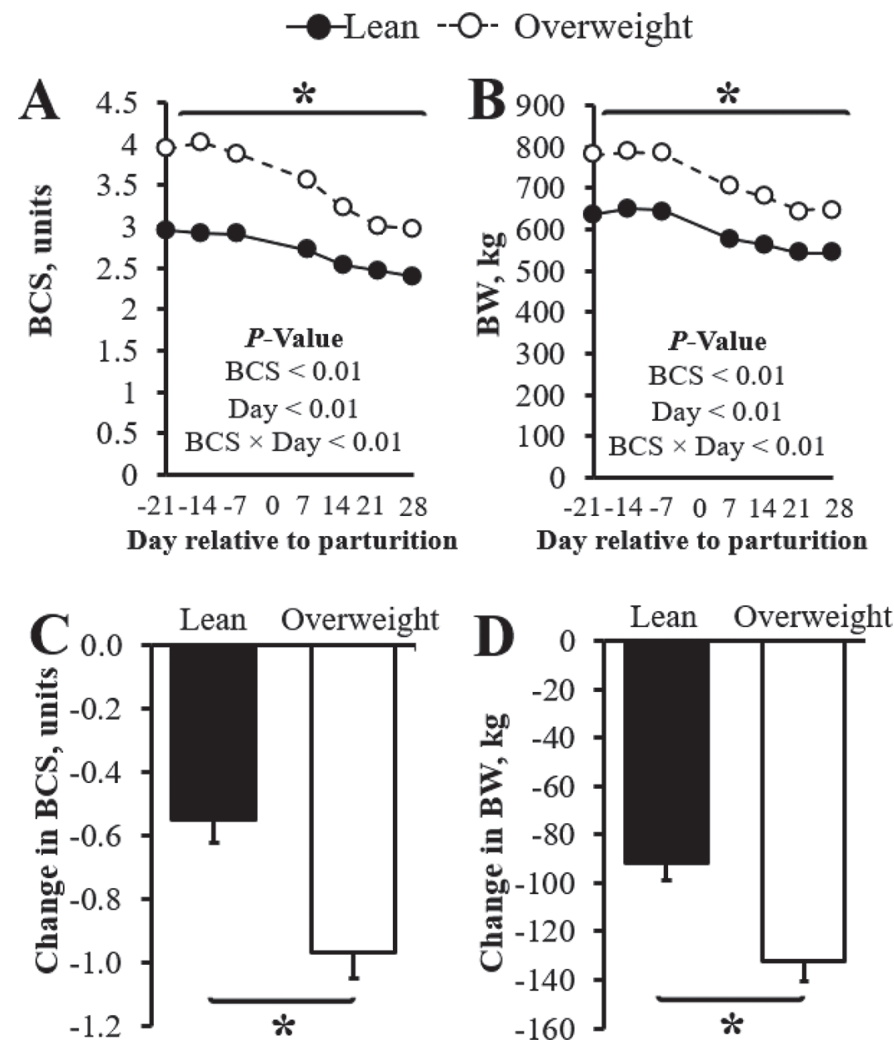

Figure 1. Effects of prepartum BCS on periparturient changes in BCS and BW in dairy cows classified as lean or overweight prepartum $(\mathrm{d}-28)$. Status of (A) BCS and (B) BW during the transition from gestation to lactation. Total loss in (C) BCS and (D) BW between $\mathrm{d}-21$ and 28 relative to parturition. Data are presented as LSM \pm SEM. ${ }^{*} P<0.01$.
Overweight cows tended to be less insulin sensitive postpartum compared with lean cows according to a reduction in the glucose infusion rate during the HEC ( $P$ $<0.10$; Figure 5A). When using the insulin sensitivity index as a measure of systemic insulin sensitivity to account for differences in insulin status, overweight cows were significantly less insulin sensitive compared with lean cows postpartum $(P<0.01$; Figure 5B). Such findings contradict recent findings using glucose and insulin challenges as a means to assess insulin sensitivity (Rico et al., 2017; Jaakson et al., 2018). Specifically, elevated prepartum BCS did not modify insulin-stimulated reductions in glucose or adipose tissue insulin sensitivity postpartum (Jaakson et al., 2018). In alignment with the current findings, Zachut et al. (2013) demonstrated that cows prone to excessive weight loss experience greater adipose-specific insulin resistance. The approximately 2 -fold increase in circulating insulin levels obtained with the current HEC application may be a better reflection of insulin sensitivity status.

We applied a previously developed SEC-FPLC method to rapidly isolate bovine serum lipoproteins containing major lipid classes and sphingolipids such as ceramide (Phipps et al., 2017). Table 1 and Supplemental Table S2 (https://doi.org/10.3168/jds.2018-15850) define the composition of major lipids in each pooled TAG-rich lipoprotein, LDL, and buoyant HDL fraction. The TAG-rich lipoprotein fraction primarily contained TAG $(57,35$, and $36 \%$ of total lipid components at $\mathrm{d}$ $-8,0$, and 10 , respectively), whereas LDL principally contained cholesterol (nonesterified and esterified) and phospholipids in equal proportions. Similar lipoprotein lipid composition has been observed in dairy cows using ultracentrifugation for lipoprotein isolation (Raphael et al., 1973; Van den Top et al., 2005). The concentrations of TAG within TAG-rich lipoprotein fractions decreased at parturition and remained low by $\mathrm{d} 10$ postpartum $(P<0.01)$. In contrast, total cholesterol and phospholipids within LDL fractions were lowest at parturition $(P<0.05)$. The reduction in major lipid classes of these lipoproteins may reflect a decrease in the number of lipoprotein particles, which may indicate limited secretion from the liver. Alternatively or in parallel, the postpartum reduction in TAG within TAGrich lipoproteins may be due to the enhanced clearance of TAG from the mammary gland for milk synthesis or a decrease in hepatic TAG secretion within VLDL (Barber et al., 1997). With the exception of lower TAGrich lipoprotein cholesterol in overweight cows $(P=$ 0.04), elevated prepartum BCS did not overtly modify lipid composition of TAG-rich or LDL lipoprotein fractions (Table 1). One potential explanation for the observed reduction in TAG-rich lipoprotein cholesterol in 
- Lean aOverweight
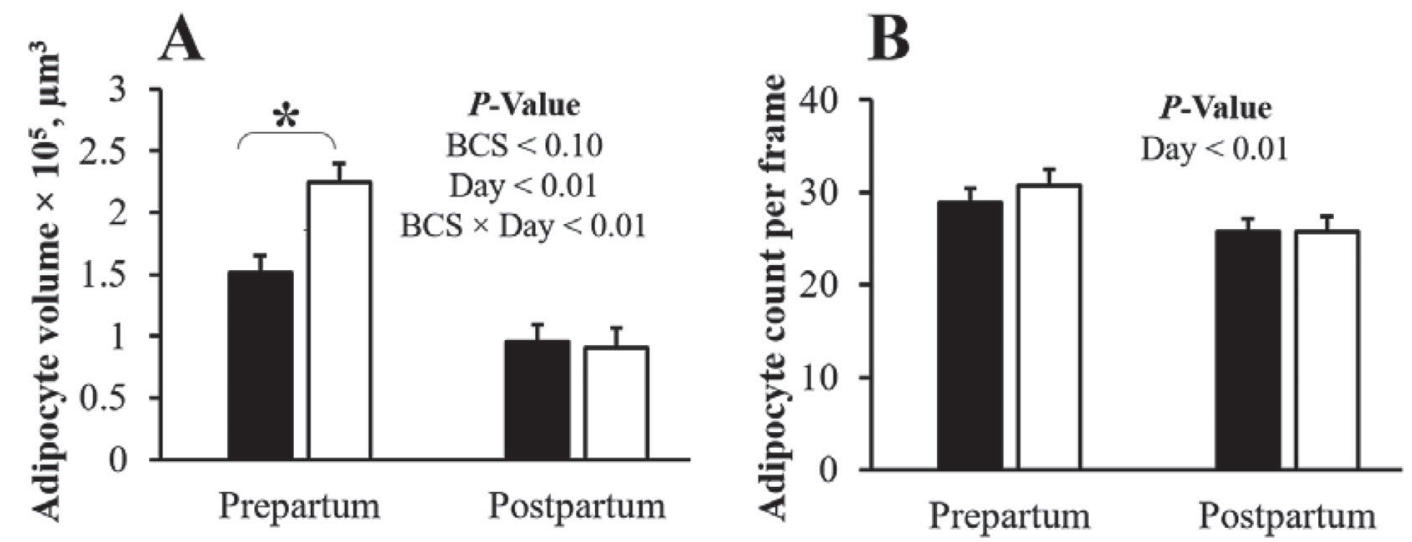

Figure 2. Effects of prepartum BCS on subcutaneous adipose tissue adipocyte volume and counts in dairy cows classified as lean or overweight prepartum $(\mathrm{d}-28)$. Adipocyte $(\mathrm{A})$ volume and $(\mathrm{B})$ counts per $743.8-\times 557.9-\mu \mathrm{m}$ reading frame at $200 \times$ magnification measured in subcutaneous adipose tissue at $\mathrm{d}-8$ and 10 relative to parturition. Data are presented as LSM \pm SEM. ${ }^{*} P<0.01$.

overweight cows is that hepatic cholesterol availability was lower. In support, Loor et al. (2007) reported that the hepatic expression of genes involved in cholesterol synthesis (i.e., 3-hydroxy-3-methylglutaryl-coenzyme A reductase and sterol-C4-methyl oxidase-like) is downregulated during ketosis. Similar mechanisms may be involved in the present study because overweight cows exhibited elevated plasma BHB levels relative to lean cows.

A major determinant for circulating ceramide concentrations is the hepatic action of microsomal triglyceride transfer protein (Lightle et al., 2003). Specifically, microsomal triglyceride transfer protein may transfer ceramide and sphingomyelin (SM) to apolipoprotein
B-containing lipoproteins including VLDL to facilitate their secretion (Iqbal et al., 2015). In our study, we observed marked reductions in TAG-rich lipoprotein C16:0- and C24:0-linked ceramides as well as monohexosylceramide (GlcCer) and lactosylceramide (LacCer) concentrations during the transition period $(P<$ 0.01; Figure $5 \mathrm{~A}-\mathrm{F}$ ). For instance, we observed a $65 \%$ decrease in TAG-rich lipoprotein C24:0-ceramide from $\mathrm{d}-8$ prepartum to calving. For the most part, TAGrich lipoprotein ceramide, GlcCer, and LacCer levels remained low by d 10 postpartum. Similar observations were observed for TAG-rich lipoprotein C16:0- and C24:0-SM (Supplemental Figure S3A and B; https:/ /doi.org/10.3168/jds.2018-15850). Confirming our ob-

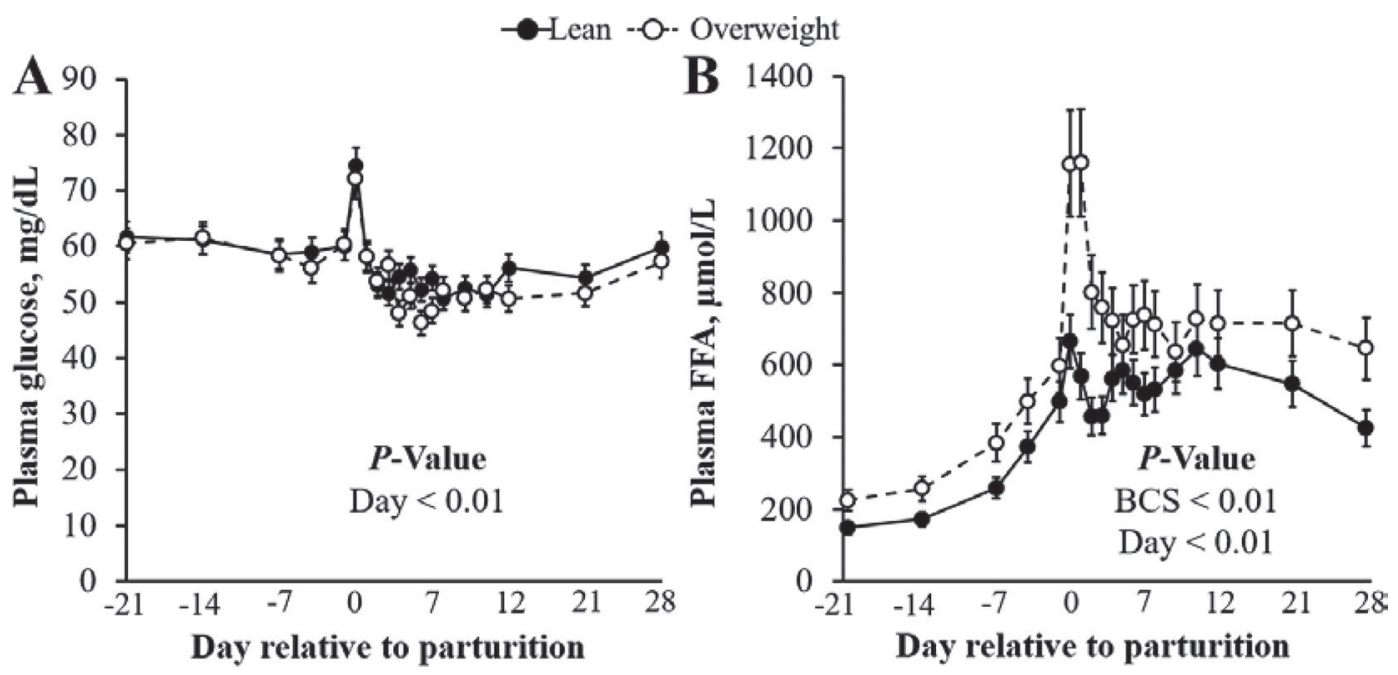

Figure 3. Effects of prepartum BCS on plasma glucose and free fatty acids (FFA) in dairy cows classified as lean or overweight prepartum (d -28). Plasma (A) glucose and (B) FFA concentrations from d -21 to 28 relative to parturition. Data are presented as LSM \pm SEM. 


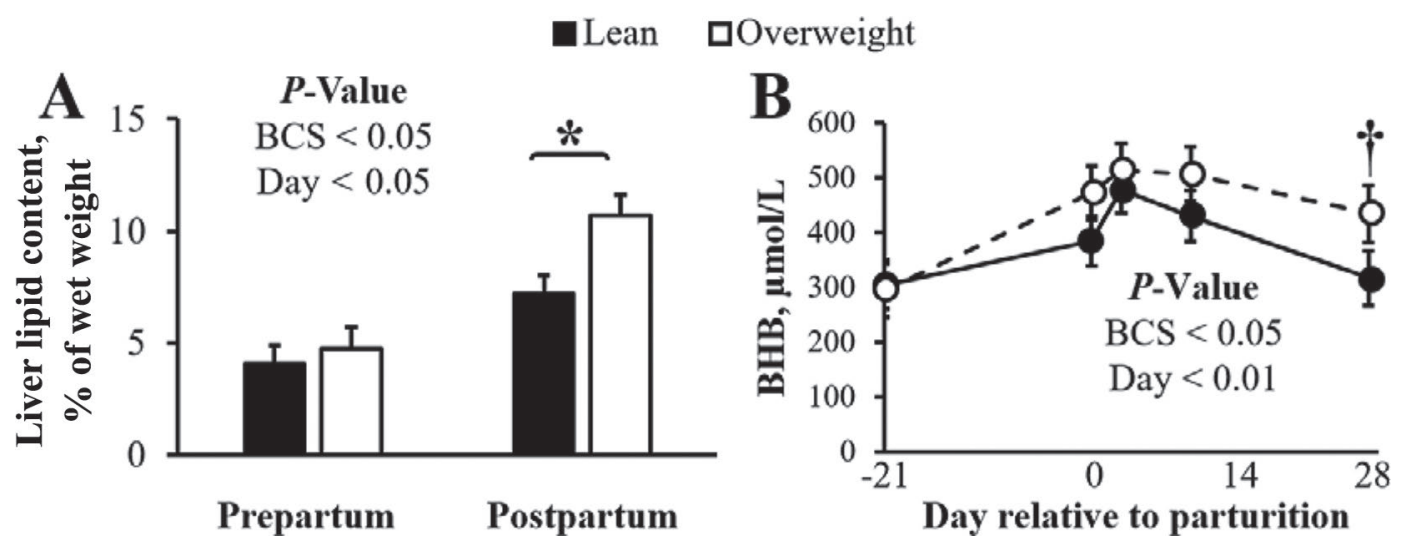

Figure 4. Effects of prepartum BCS on liver lipid content and circulating BHB in dairy cows classified as lean or overweight prepartum (d -28). (A) Prepartum ( $\mathrm{d}-8$ ) and postpartum (d 10) liver lipid content and (B) plasma BHB concentrations from d -21 to 28 relative to parturition. Data are presented as LSM \pm SEM. $* P<0.05 ; \dagger P<0.10$.

servations in plasma (Rico et al., 2015, 2017), serum lipoprotein C24:0-ceramide and C16:0-SM were the most abundant sphingolipids quantified relative to C16: 0-ceramide, any other glycosylated ceramide, or C24:0 -SM. We consider that the presence of ceramide and SM within TAG-rich lipoproteins was likely due to their hepatic synthesis from lipolytic-derived FFA (Davis et al., 2017). The ability to synthesize C24:0-ceramide monohexosylceramide from SFA is likely due to the action of elongases, which elongate palmitoyl-CoA to lignoceroylCoA (Ohno et al., 2010). Indeed, others have observed that palmitic acid treatment stimulates ceramide and SM secretion from primary rat hepatocytes (Merrill et al., 1995). Interestingly, the ability of palmitic acid to promote hepatic ceramide secretion may also involve the upregulation of MTP (Konstantynowicz-Nowicka et al., 2015). Such mechanisms may also be at work in the cow, considering that supplemental palmitic acid (Rico et al., 2016) or nutrient restriction (Davis et al., 2017) can increase hepatic and circulating ceramide. Moreover, palmitic acid increases de novo ceramide synthesis in bovine neonatal hepatocyte cultures (McFadden et al., 2018). Based on these previous studies, we would expect TAG-rich lipoprotein ceramide levels to increase during the transition; however, the postpartum removal of TAG from VLDL by the mammary gland likely results in the accrual of ceramide and SM within LDL. The cow's limited capacity to secrete VLDL (which contain ceramide) also deserves consideration (Pullen et al., 1990). Although we cannot conclusively confirm
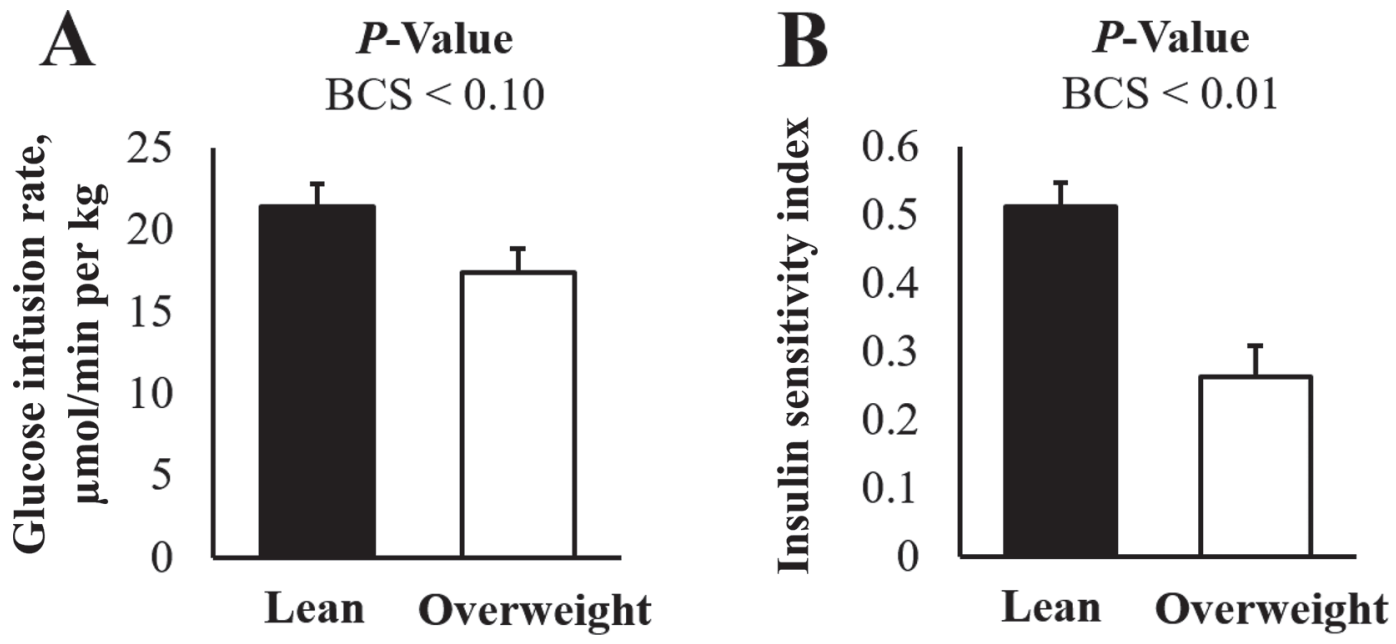

Figure 5. Measures of systemic insulin sensitivity at d 12 postpartum in dairy cows classified as lean or overweight prepartum (d -28$)$. (A) Glucose infusion rate during a hyperinsulinemic-euglycemic clamp. (B) Insulin sensitivity index (SI) was calculated as follows: $\mathrm{SI}_{\text {Clamp }}=$ glucose infusion rate/[(steady-state glucose $) \times($ steady-state insulin - basal insulin) $]$. Data are presented as LSM \pm SEM. 
Table 1. Lipid concentrations and content of serum triacylglycerol (TAG)-rich lipoprotein and low-density lipoprotein (LDL) fractions in peripartal dairy cattle

\begin{tabular}{|c|c|c|c|c|c|c|c|c|c|c|}
\hline \multirow{2}{*}{ Pooled fraction } & \multicolumn{6}{|c|}{$\mathrm{BCS}^{1}$} & \multirow{2}{*}{ SEM } & \multirow{2}{*}{\multicolumn{3}{|c|}{$\begin{array}{c}\text { Main effects } \\
P \text {-value }\end{array}$}} \\
\hline & \multicolumn{2}{|c|}{$\mathrm{d}-8$} & \multicolumn{2}{|r|}{ d 0} & \multicolumn{2}{|r|}{ d 10} & & & & \\
\hline \multicolumn{11}{|c|}{ TAG-rich, mg/dL } \\
\hline TAG & 2.36 & 2.48 & 0.40 & 0.37 & 0.50 & 0.46 & 0.08 & 0.85 & $<0.01$ & 0.69 \\
\hline Cholesterol & 0.83 & 0.71 & 0.33 & 0.28 & 0.44 & 0.36 & 0.03 & 0.04 & $<0.01$ & 0.80 \\
\hline TAG & 0.27 & 0.29 & 0.16 & 0.16 & 0.13 & 0.14 & 0.01 & 0.68 & $<0.01$ & 0.82 \\
\hline Cholesterol & 7.66 & 6.63 & 7.14 & 6.06 & 9.02 & 7.60 & 0.41 & 0.21 & 0.03 & 0.70 \\
\hline \multirow{2}{*}{\multicolumn{11}{|c|}{ TAG-rich, $\%$ of total }} \\
\hline & & & & & & & & & & \\
\hline TAG & 52.1 & 60.8 & 30.3 & 39.7 & 35.8 & 35.4 & 3.16 & 0.04 & $<0.01$ & 0.22 \\
\hline Cholesterol & 18.7 & 17.0 & 26.4 & 27.4 & 32.2 & 27.7 & 1.89 & 0.35 & $<0.01$ & 0.37 \\
\hline Phospholipid & 27.8 & 21.4 & 40.4 & 35.0 & 29.3 & 35.4 & 2.96 & 0.40 & $<0.01$ & 0.04 \\
\hline
\end{tabular}

${ }^{1}$ Study groups were lean and overweight Holstein cows with a BCS of $2.96 \pm 0.16$ and $3.93 \pm 0.30$, respectively, at enrollment (d -28 before expected calving). Data are presented as LSM \pm SEM.

that our TAG-rich fraction solely comprised VLDL particles, ceramide and SM detected are likely within liver-derived VLDL and not chylomicrons of intestinal origin because the amide bond of sphingolipids is hydrolyzed by intestinal ceramidase (Olsson et al., 2004). In further support, ceramide represents $0.3 \%$ of polar surface lipids of chylomicrons (Yang et al., 1992).

Because LDL ceramide directly antagonizes insulin signaling and systemic glucose utilization (Boon et al., 2013), we also characterized changes in LDL C16:0- and C24:0-linked ceramide, GlcCer, and LacCer (Figure 6). In human serum fractionated using SECFPLC, ceramide is predominantly found within LDL, although VLDL ceramide content is relatively high (Wiesner et al., 2009; Boon et al., 2013). Similarly, the concentrations of C16:0- and C24:0-ceramide were comparable between TAG-rich lipoprotein and LDL fractions (Figures 5 and 6). We observed consistent elevations in the serum concentrations of LDL C16:0- and C24:0-ceramides ( $\sim 60 \%$ increase by d 10 relative to $\mathrm{d}$ -8), C24:0-GlcCer, and C16:0- and C24:0-LacCer as cows transitioned from gestation to lactation $(P<$ 0.05). Moreover, C16:0-GlcCer levels in LDL tended to increase with time $(P<0.10)$. Supporting the possibility that VLDL ceramide is converted to LDL ceramide after TAG removal, the ratios of LDL ceramide to TAGrich ceramide increased with time $(P<0.01$; Figure 7$)$. For example, the ratio of LDL to TAG-rich lipoprotein C24:0-ceramide increased by $226 \%$ by parturition relative to $\mathrm{d}-8$ prepartum $(P<0.01)$. Although not the focus of this study, ceramides within the buoyant HDL fraction also increased during the transition $(P<0.05$; Supplemental Figure S4, https://doi.org/10.3168/jds .2018-15850). However, prepartum adiposity did not influence HDL C16:0-ceramide concentrations.

The origin of ceramides within LDL is not clear. We hypothesize that the increase in circulating ceramides observed in transition cows is likely derived from a combination of hepatic de novo ceramide synthesis and their secretion as well as the hydrolysis of SM by proinflammatory cues (Rico et al., 2015, 2017). In support, elevations in hepatic FFA supply develop with increases in circulating dihydro-ceramides (intermediates of de novo synthesis; Rico et al., 2015), whereas reductions in circulating SM have been observed at parturition (Rico et al., 2017). Within the context of the current work, we contemplated whether the actions of sphingomyelinases were involved. First, zinc-dependent secretory (acid) sphingomyelinase resides on the surface of arterial walls (Schissel et al., 1998), and LDL may contain neutral sphingomyelinase activity (Holopainen et al., 2000; Kinnunen and Holopainen, 2002). The activity of either sphingomyelinase holds the potential to hydrolyze SM to ceramide. Serum concentrations of LDL C16:0- and C24:0-SM increased along with LDL ceramide $(P<$ 0.01; Supplemental Figure S3C and D, https://doi.org/ 10.3168/jds.2018-15850), suggesting that the increase in LDL ceramide is due to hepatic de novo ceramide synthesis from FFA substrate. In support, levels of LDL C16:0- and C24:0-ceramide were weakly correlated with 
plasma FFA levels $(\mathrm{r}=0.34$ and 0.41 , respectively; $P$ $<0.05$ ). However, we also observed an increase in the ratio of LDL to SM C16:0-ceramide at parturition relative to $\mathrm{d}-8$ and 10 , suggesting that SM hydrolysis may also be contributing to the LDL ceramide pool $(P<$ 0.05; Supplemental Figure S5, https://doi.org/10.3168/ jds.2018-15850; Boulgaropoulos et al., 2010). This evidence supports that both de novo ceramide synthesis and SM hydrolysis may be contributing to the increase in LDL ceramide levels during the peripartum period. Future work will need to confirm the origin of ceramide within LDL in periparturient dairy cows and assess the involvement of sphingomyelinases.

Previous studies have demonstrated that prepartum adiposity increases peripartal ceramide concentrations in whole plasma (Rico et al., 2015, 2017). Indeed, obesity increases plasma ceramides in humans (Haus et al., 2009). Importantly, obesity and diabetes do not modify VLDL ceramide levels in humans (Boon et al., 2013), and LDL ceramide is elevated only in obese diabetics and not in lean or obese patients who are insulin sensitive. In the present study, prepartum BCS status had minimal effects on sphingolipid concentrations found within TAG-rich lipoprotein (Figure 5) or LDL fractions (Figure 6). We did observe that overweight cows had lower serum levels of TAG-rich lipoprotein C16:0-ceramide and C24:0-GlcCer relative to lean cows $(P<0.05$; Figure $5 \mathrm{~A}$ and $\mathrm{D})$. Interestingly, we previously observed lower prepartum hepatic concentrations of C16:0- and C24:0-ceramide in overweight cows
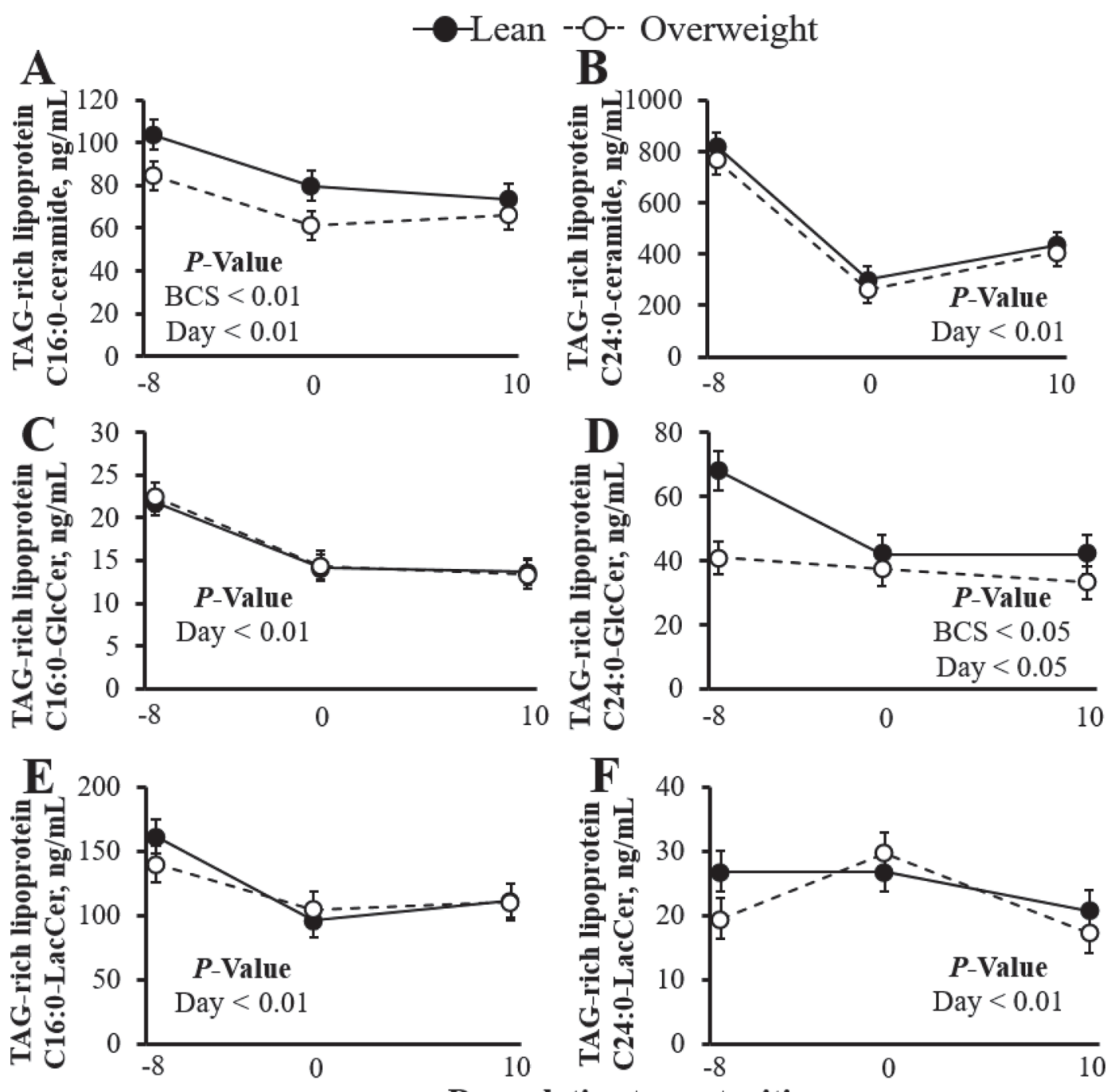

Day relative to parturition

Figure 6. Serum triacylglycerol (TAG)-rich lipoprotein ceramide concentrations in dairy cows classified as lean or overweight prepartum (d -28). Concentrations of (A) C16:0-ceramide, (B) C24:0-ceramide, (C) C16:0-monohexosylceramide (GlcCer), (D) C24:0-GlcCer, (E) C16:0 -lactosylceramide (LacCer), and (F) C24:0-LacCer in low-density lipoprotein fractions. Data are presented as LSM \pm SEM. 
relative to lean cows (Rico et al., 2017). Furthermore, overweight cows experienced a decrease in LDL C16:0 -ceramide concentrations from parturition to d $10(P$ $=0.05)$, a variable that numerically increased in lean cows (d 0 vs. $\mathrm{d} 10 ; P=0.21$ ). Also, the postpartum ratio of LDL to TAG-rich lipoprotein C16:0-ceramide tended to be higher in cows with elevated prepartum adiposity $(P=0.10 ;$ Figure 8$)$. In contrast to these findings, prepartum LDL C24:0-ceramide concentrations were $43 \%$ greater in overweight cows $(P<0.05)$ relative to lean cows. Circulating C24:0-ceramide levels are elevated in whole plasma collected from cows with heightened prepartum BCS (Rico et al., 2015, 2017).

Considering our previous work evaluating whole plasma (Rico et al., 2015, 2017), we were surprised not to detect major differences in LDL ceramide levels with varying prepartum BCS and postpartum insulin sensitivity. One consideration is that internal fat deposition was not different between prepartum BCS groups. However, we recognized that BCS has been shown to be positively correlated with masses of omental, mesenteric, and perirenal adipose depots (Drackley et al., 2014). We also consider other sources of circulating ceramide that may explain why overweight cows experience elevations in whole-plasma ceramide levels (Rico et al., 2015, 2017) relative to lean cows. Most notably, lipoprotein-deficient serum contains approximately $15 \%$ of serum ceramides (Lightle et al., 2003). These ceramides may be found in extracellular vesicles, such as exosomes, which bud off from the plasma membrane

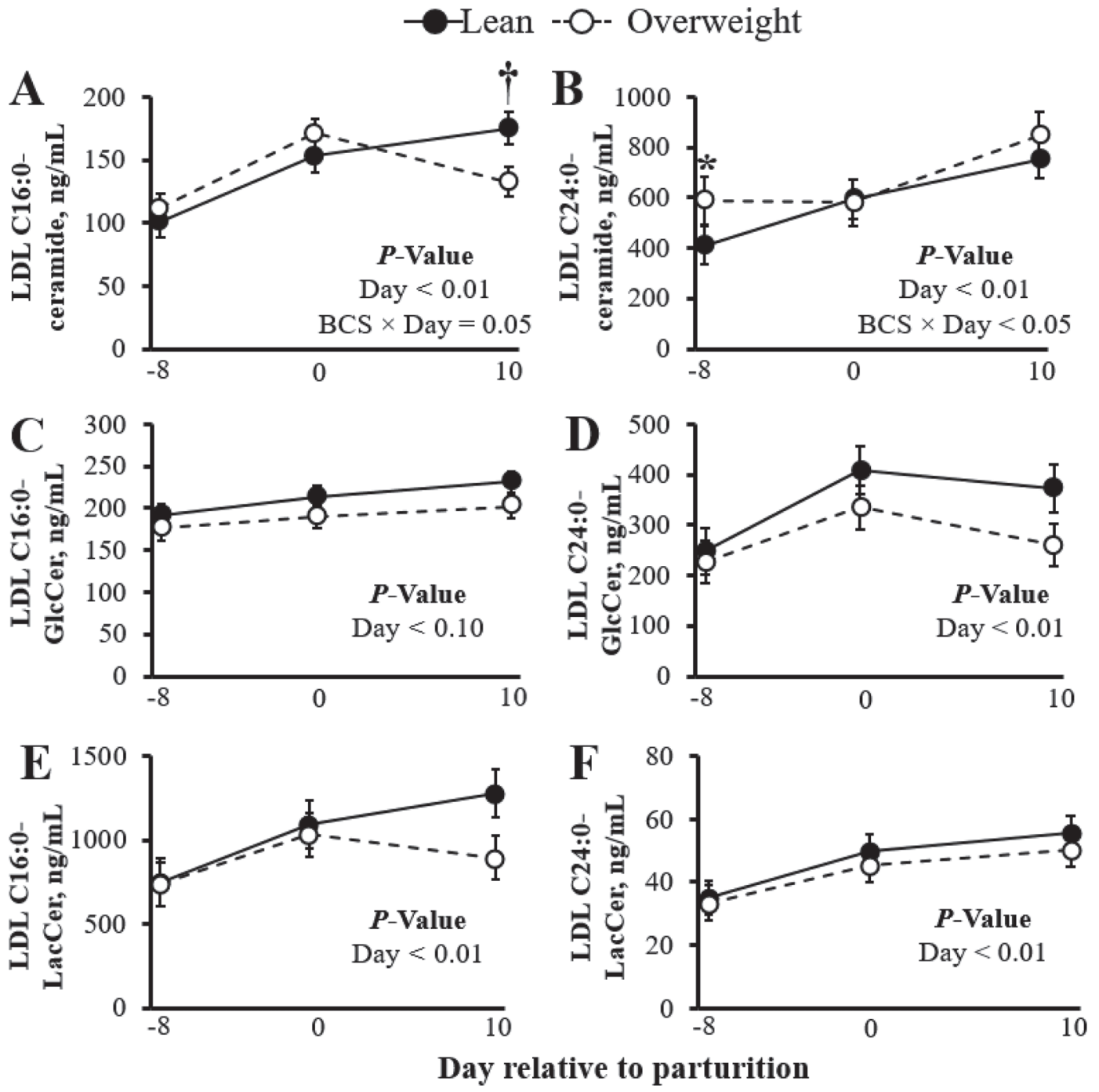

Figure 7. Serum low-density lipoprotein (LDL) ceramide concentrations in dairy cows classified as lean or overweight prepartum (d -28). Concentrations of (A) C16:0-ceramide, (B) C24:0-ceramide, (C) C16:0-monohexosylceramide (GlcCer), (D) C24:0-GlcCer, (E) C16:0 -lactosylceramide (LacCer), and (F) C24:0-LacCer in LDL fractions. Data are presented as LSM \pm SEM. ${ }^{*} P<0.05 ; \dagger P<0.10$. 


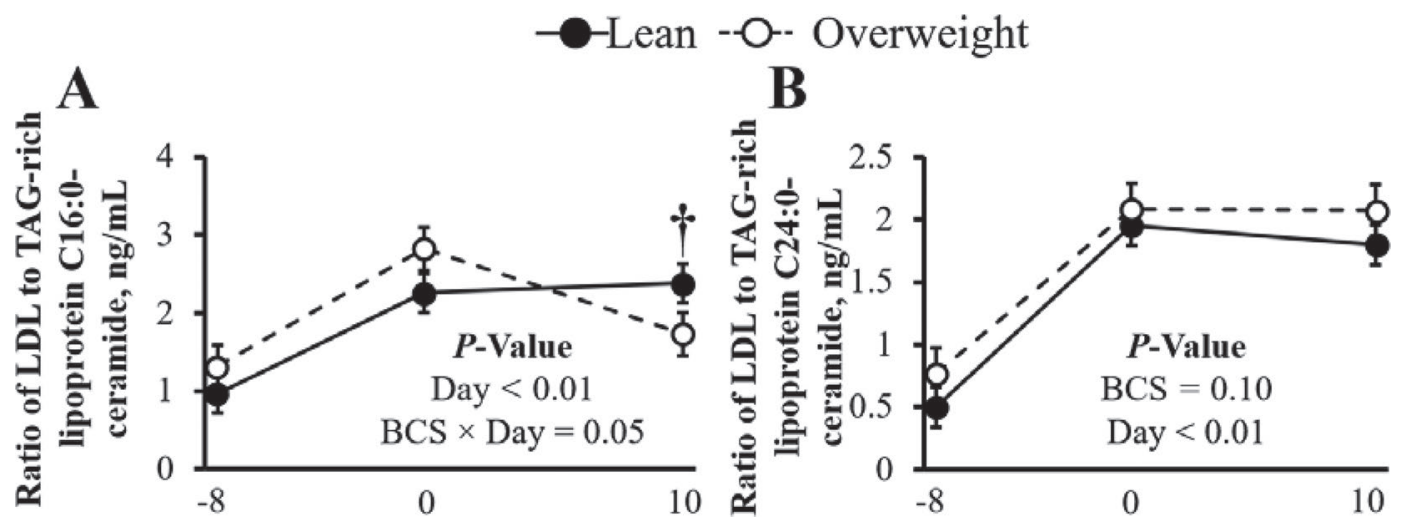

Figure 8. Serum ratios of low-density lipoprotein (LDL) to triacylglycerol (TAG)-rich lipoprotein (A) C16:0-ceramide and (B) C24:0 -ceramide in dairy cows classified as lean or overweight prepartum $(\mathrm{d}-28)$. Data are presented as LSM $\pm \mathrm{SEM} . \dagger P<0.10$.

for intercellular communication (Trajkovic et al., 2008). They may also be relevant in transition cows because extracellular vesicle release is increased by lipotoxicity during inflammatory fatty liver disease (Kornek et al., 2012), and hepatic ceramides trigger exosome budding (Trajkovic et al., 2008). Although data are limited, researchers have also hypothesized that ceramide may also be secreted from adipose tissue (Holland et al., 2007; Cowart, 2009). Nevertheless, the possibility remains that LDL ceramide may downregulate insulin action in all cows even though it does not appear to be responsive to prepartum BCS status.

\section{CONCLUSIONS}

Circulating LDL ceramide concentrations increase in dairy cows transitioning from gestation to lactation. Such findings are of potential importance with the understanding that LDL ceramide causes insulin resistance in nonruminants. Even though LDL ceramide accrual developed with elevations in circulating FFA and hepatic lipid accumulation and overweight cows were less insulin sensitive compared with lean cows postpartum, prepartum adiposity status did not overtly modify lipoprotein ceramide levels. These findings suggest that LDL ceramide may not be a feature of the pathophysiology of obesity-associated insulin antagonism in cows. However, the possibility exists that postpartum LDL ceramide accrual represents a homeorhetic response to inhibit insulin sensitivity as cows transition to lactation. Moving forward, a more mechanistic evaluation is required to determine whether LDL ceramide directly antagonizes insulin signaling in dairy cows, and the role of ceramide in the somatotropic control of lactation should be investigated. The potential for adipose tissue to secrete ceramides and the role of exosomes in ceramide trafficking should also be considered.

\section{ACKNOWLEDGMENTS}

This work was supported by the Agriculture and Food Research Initiative Competitive Grant (no. 201667015-24582) from the USDA National Institute of Food and Agriculture (Washington, DC) and the Ruby Distinguished Doctoral Fellows Program at West Virginia University (Morgantown). The authors gratefully acknowledge Devon Henry (West Virginia University) for extracting the liver lipid, Deborah McLaughlin (West Virginia University) for processing the adipose tissue histology samples, and the VanGilder family at DoVan Farms for their participation.

\section{REFERENCES}

AOAC International. 1995. Official Methods of Analysis of AOAC International, Vol. 1. Agriculture Chemicals, Contaminants, Drugs. 16th ed. AOAC International, Arlington, VA.

Barber, M. C., R. A. Clegg, M. T. Travers, and R. G. Vernon. 1997. Lipid metabolism in the lactating mammary gland. Biochim. Biophys. Acta 1347:101-126.

Bauman, D. E., and W. B. Currie. 1980. Partitioning of nutrients during pregnancy and lactation: A review of mechanisms involving homeostasis and homeorhesis. J. Dairy Sci. 63:1514-1529.

Bell, A. W. 1995. Regulation of organic nutrient metabolism during transition from late pregnancy to early lactation. J. Anim. Sci. $73: 2804-2819$

Boon, J., A. J. Hoy, R. Stark, R. D. Brown, R. C. Meex, D. C. Henstridge, S. Schenk, P. J. Meikle, J. F. Horowitz, B. A. Kingwell, C. R. Bruce, and M. J. Watt. 2013. Ceramides contained in LDL are elevated in type 2 diabetes and promote inflammation and skeletal muscle insulin resistance. Diabetes 62:401-410.

Boulgaropoulos, B., H. Amenitsch, P. Laggner, and G. Pabst. 2010. Implication of sphingomyelin/ceramide molar ratio on the biological activity of sphingomyelinase. Biophys. J. 99:499-506.

Cowart, L. A. 2009. Sphingolipids: Players in the pathology of metabolic disease. Trends Endocrinol. Metab. 20:34-42.

Davis, A. N., J. L. Clegg, C. A. Perry, and J. W. McFadden. 2017. Nutrient restriction increases circulating and hepatic ceramide in dairy cows displaying impaired insulin tolerance. Lipids 52:771780.

DeFronzo, R. A., J. D. Tobin, and R. Andres. 1979. Glucose clamp technique: A method for quantifying insulin secretion and resistance. Am. J. Physiol. 237:G214-G223. 
De Koster, J., W. Van Den Broeck, L. Hulpio, E. Claeys, M. Van Eetvelde, K. Hermans, M. Hostens, V. Fievez, and G. Opsomer. 2016. Influence of adipocyte size and adipose depot on the in vitro lipolytic activity and insulin sensitivity of adipose tissue in dairy cows at the end of the dry period. J. Dairy Sci. 99:2319-2328.

Drackley, J. K., R. L. Wallace, D. Graugnard, J. Vasquez, B. F. Richards, and J. J. Loor. 2014. Visceral adipose tissue mass in nonlactating dairy cows fed diets differing in energy density. J. Dairy Sci. 97:3420-3430.

Fronk, T. J., L. H. Schultz, and A. R. Hardie. 1980. Effect of dry period overconditioning on subsequent metabolic disorders and performance of dairy cows. J. Dairy Sci. 63:1080-1090.

Gearhart, M. A., C. R. Curtis, H. N. Erb, R. D. Smith, C. J. Sniffen, L. E. Chase, and M. D. Cooper. 1990. Relationship of changes in condition score to cow health in Holsteins. J. Dairy Sci. 73:31323140 .

Hara, A., and N. S. Radin. 1978. Lipid extraction of tissues with a low-toxicity solvent. Anal. Biochem. 90:420-426.

Haus, J. M., S. R. Kashyap, T. Kasumov, R. Zhang, K. R. Kelly, R. A. DeFronzo, and J. P. Kirwan. 2009. Plasma ceramides are elevated in obese subjects with type 2 diabetes and correlate with the severity of insulin resistance. Diabetes 58:337-343.

Hla, T., and R. Kolesnick. 2014. C16:0-ceramide signals insulin resistance. Cell Metab. 20:703-705.

Holland, W. L., J. T. Brozinick, L.-P. Wang, E. D. Hawkins, K. M. Sargent, Y. Liu, K. Narra, K. L. Hoehn, T. A. Knotts, A. Siesky, D. H. Nelson, S. K. Karathanasis, G. K. Fontenot, M. J. Birnbaum, and S. A. Summers. 2007. Inhibition of ceramide synthesis ameliorates glucocorticoid-, saturated-fat-, and obesity-induced insulin resistance. Cell Metab. 5:167-179.

Holopainen, J. M., O. P. Medina, A. J. Metso, and P. K. Kinnunen. 2000. Sphingomyelinase activity associated with human plasma low density lipoprotein. J. Biol. Chem. 275:16484-16489.

Hughes, J. P. 1962. A simplified instrument for obtaining liver biopsies in cattle. Am. J. Vet. Res. 23:1111-1113.

Iqbal, J., M. T. Walsh, S. M. Hammad, M. Cuchel, P. Tarugi, R. A. Hegele, N. O. Davidson, D. J. Rader, R. L. Klein, and M. M. Hussain. 2015. Microsomal triglyceride transfer protein transfers and determines plasma concentrations of ceramide and sphingomyelin but not glycosylceramide. J. Biol. Chem. 290:25863-25875.

Jaakson, H., P. Karis, K. Ling, A. Ilves-Luht, J. Samarütel, M. Henno, I. Jõudu, A. Waldmann, E. Reimann, P. Pärn, R. M. Bruckmaier, J. J. Gross, T. Kaart, M. Kass, and M. Ots. 2018. Adipose tissue insulin receptor and glucose transporter 4 expression, and blood glucose and insulin responses during glucose tolerance tests in transition Holstein cows with different body condition. J. Dairy Sci. 101:752-766.

Kinnunen, P. K., and J. M. Holopainen. 2002. Sphingomyelinase activity of LDL: A link between atherosclerosis, ceramide, and apoptosis? Trends Cardiovasc. Med. 12:37-42.

Konstantynowicz-Nowicka, K., E. Harasim, M. Baranowski, and A. Chabowski. 2015. New evidence for the role of ceramide in the development of hepatic insulin resistance. PLoS One 10:e0116858.

Kontush, A., and M. J. Chapman. 2010. Antiatherogenic function of HDL particle subpopulations: Focus on antioxidative activities. Curr. Opin. Lipidol. 21:312-318.

Kornek, M., M. Lynch, S. H. Mehta, M. Lai, M. Exley, N. H. Afdhal, and D. Schuppan. 2012. Circulating microparticles as diseasespecific biomarkers of severity of inflammation in patients with hepatitis $\mathrm{C}$ or nonalcoholic steatohepatitis. Gastroenterology 143:448-458

Lightle, S., R. Tosheva, A. Lee, J. Queen-Baker, B. Boyanovsky, S. Shedlofsky, and M. Nikolova-Karakashian. 2003. Elevation of ceramide in serum lipoproteins during acute phase response in humans and mice: Role of serine-palmitoyl transferase. Arch. Biochem. Biophys. 419:120-128.

Loor, J. J., R. E. Everts, M. Bionaz, H. M. Dann, D. E. Morin, R. Oliveira, S. L. Rodriguez-Zas, J. K. Drackley, and H. A. Lewin. 2007. Nutrition-induced ketosis alters metabolic and signaling gene networks in liver of periparturient dairy cows. Physiol. Genomics 32:105-116.
McCarthy, S., D. Berry, P. Dillon, M. Rath, and B. Horan. 2007. Influence of Holstein-Friesian strain and feed system on body weight and body condition score lactation profiles. J. Dairy Sci. 90:1859-1869.

McFadden, J. W., J. Rico, J. Erb, and H. White. 2018. Inhibition of serine palmitoyltransferase prevents palmitic acid-induced ceramide synthesis in bovine primary hepatocytes. J. Dairy Sci. 101(E-suppl.):105. (Abstr.)

Merrill, A. H., S. Lingrell, E. Wang, M. Nikolova-Karakashian, T. R. Vales, and D. E. Vance. 1995. Sphingolipid biosynthesis de novo by rat hepatocytes in culture. Ceramide and sphingomyelin are associated with, but not required for, very low density lipoprotein secretion. J. Biol. Chem. 270:13834-13841.

Muniyappa, R., S. Lee, H. Chen, and M. J. Quon. 2007. Current approaches for assessing insulin sensitivity and resistance in vivo: Advantages, limitations, and appropriate usage. Am. J. Physiol. Endocrinol. Metab. 294:E15-E26.

Ohno, Y., S. Suto, M. Yamanaka, Y. Mizutani, S. Mitsutake, Y. Igarashi, T. Sassa, and A. Kihara. 2010. ELOVL1 production of C24 acyl-CoAs is linked to C24 sphingolipid synthesis. Proc. Natl. Acad. Sci. USA 107:18439-18444.

Olsson, M., R.-D. Duan, L. Ohlsson, and A. Nilsson. 2004. Rat intestinal ceramidase: Purification, properties, and physiological relevance. Am. J. Physiol. Gastrointest. Liver Physiol. 287:G929G937.

Phipps, Z. C., F. Seck, A. N. Davis, J. E. Rico, and J. W. McFadden. 2017. Characterization of ceramide in bovine lipoproteins. J. Dairy Sci. 100:8602-8608.

Piepenbrink, M. S., and T. Overton. 2003. Liver metabolism and production of cows fed increasing amounts of rumen-protected choline during the periparturient period. J. Dairy Sci. 86:1722-1733.

Pullen, D. L., J. Liesman, and R. Emery. 1990. A species comparison of liver slice synthesis and secretion of triacylglycerol from nonesterified fatty acids in media. J. Anim. Sci. 68:1395-1399.

Raphael, B. C., P. Dimick, and D. Puppione. 1973. Lipid characterization of bovine serum lipoproteins throughout gestation and lactation. J. Dairy Sci. 56:1025-1032.

Rico, J. E., V. V. R. Bandaru, J. M. Dorskind, N. J. Haughey, and J. W. McFadden. 2015. Plasma ceramides are elevated in overweight Holstein dairy cows experiencing greater lipolysis and insulin resistance during the transition from late pregnancy to early lactation. J. Dairy Sci. 98:7757-7770.

Rico, J. E., S. L. Giesy, N. J. Haughey, Y. R. Boisclair, and J. W. McFadden. 2018a. Intravenous triacylglycerol infusion promotes ceramide accumulation and hepatic steatosis in dairy cows. J. Nutr. 148:1529-1535.

Rico, J. E., A. T. Mathews, J. Lovett, N. J. Haughey, and J. W. McFadden. 2016. Palmitic acid feeding increases ceramide supply in association with increased milk yield, circulating nonesterified fatty acids, and adipose tissue responsiveness to a glucose challenge. J. Dairy Sci. 99:8817-8830.

Rico, J. E., W. A. Myers, D. J. Laub, A. N. Davis, Q. Zeng, and J. W. McFadden. 2018b. Hot topic: Ceramide inhibits insulin sensitivity in primary bovine adipocytes. J. Dairy Sci. 101:3428-3432.

Rico, J. E., S. Saed Samii, A. T. Mathews, J. Lovett, N. J. Haughey, and J. W. McFadden. 2017. Temporal changes in sphingolipids and systemic insulin sensitivity during the transition from gestation to lactation. PLoS One 12:e0176787.

Roche, J. R., D. Berry, and E. Kolver. 2006. Holstein-Friesian strain and feed effects on milk production, body weight, and body condition score profiles in grazing dairy cows. J. Dairy Sci. 89:35323543.

Roche, J. R., D. Berry, J. Lee, K. Macdonald, and R. Boston. 2007. Describing the body condition score change between successive calvings: A novel strategy generalizable to diverse cohorts. J. Dairy Sci. 90:4378-4396.

Schissel, S. L., G. A. Keesler, E. H. Schuchman, K. J. Williams, and I. Tabas. 1998. The cellular trafficking and zinc dependence of secretory and lysosomal sphingomyelinase, two products of the acid sphingomyelinase gene. J. Biol. Chem. 273:18250-18259. 
Schoenberg, K. M., R. M. Ehrhardt, and T. R. Overton. 2012. Effects of plane of nutrition and feed deprivation on insulin responses in dairy cattle during late gestation. J. Dairy Sci. 95:670-682.

Sechen, S. J., F. R. Dunshea, and D. E. Bauman. 1990. Somatotropin in lactating cows: Effect on response to epinephrine and insulin. Am. J. Physiol. 258:E582-E588.

Thissen, J. P., J. M. Ketelslegers, and L. E. Underwood. 1994. Nutritional regulation of the insulin-like growth factors. Endocr. Rev. 15:80-101.

Trajkovic, K., C. Hsu, S. Chiantia, L. Rajendran, D. Wenzel, F. Wieland, P. Schwille, B. Brügger, and M. Simons. 2008. Ceramide triggers budding of exosome vesicles into multivesicular endosomes. Science 319:1244-1247.

Treacher, R. J., I. M. Reid, and C. J. Roberts. 1986. Effect of body condition at calving on the health and performance of dairy cows. Anim. Prod. 43:1-6.

Van den Top, A. M., A. VanTol, H. Jansen, M. J. Geelen, and A. C. Beynen. 2005. Fatty liver in dairy cows post partum is associated with decreased concentration of plasma triacylglycerols and decreased activity of lipoprotein lipase in adipocytes. J. Dairy Res. $72: 129-137$.
Watt, M. J., A. Barnett, C. Bruce, S. Schenk, J. Horowitz, and A Hoy. 2012. Regulation of plasma ceramide levels with fatty acid oversupply: Evidence that the liver detects and secretes de novo synthesised ceramide. Diabetologia 55:2741-2746.

Wiesner, P., K. Leidl, A. Boettcher, G. Schmitz, and G. Liebisch. 2009. Lipid profiling of FPLC- separated lipoprotein fractions by electrospray ionization tandem mass spectrometry. J. Lipid Res. 50:574-585.

Wildman, E., G. Jones, P. Wagner, R. Boman, H. Troutt Jr., and T. Lesch. 1982. A dairy cow body condition scoring system and its relationship to selected production characteristics. J. Dairy Sci. 65:495-501.

Yang, L. Y., A. Kuksis, J. Myher, and H. Pang. 1992. Surface components of chylomicrons from rats fed glyceryl or alkyl esters of fatty acids: Minor components. Lipids 27:613-618.

Zachut, M., H. Honig, S. Striem, Y. Zick, S. Boura-Halfon, and U. Moallem. 2013. Periparturient dairy cows do not exhibit hepatic insulin resistance, yet adipose-specific insulin resistance occurs in cows prone to high weight loss. J. Dairy Sci. 96:5656-5669. 